\title{
Desenvolvimento de uma proposta de formação de professores sobre a Pesquisa em Sala de Aula na Educação Infantil
}

\section{Development of a teacher training proposal on Survey into the Classroom in Early Childhood Education}

\author{
Carla Hax Hartleben (carlahax@gmail.com) \\ Universidade Federal do Rio Grande - FURG - Programa de Pós-graduação em Ensino de Ciências \\ Exatas
}

Fernanda Trombetta (fernandatrombetta@ furg.br)

Universidade Federal do Rio Grande - FURG - Escola de Química e Alimentos - EQA

\author{
Marcus Eduardo Maciel Ribeiro (profmarcus@yahoo.com.br) \\ Instituto Federal Sul-rio-grandense - IFSul
}

\begin{abstract}
Resumo: Ao ser planejada a rotina e pensada as atividades para crianças espera-se abranger o seu desenvolvimento integral, observando as singularidades e as características. Sugere-se que sejam observados questionamentos, curiosidades e a construção do conhecimento, as quais elas desenvolvem ainda na infância. Nessa perspectiva, a questão que norteou a pesquisa é: $O$ que emerge sobre a Pesquisa em Sala de Aula pelos educadores que atuam na Educação Infantil nas escolas municipais de Igrejinha-RS? Para o desenvolvimento da pesquisa foram convidados os Educadores Multimeios da rede municipal de Igrejinha-RS, que atuam com crianças de quatro a seis anos nas Escolas Municipais de Educação Infantil e de Ensino Fundamental. O objetivo geral foi proporcionar uma discussão reflexiva acerca da Pesquisa em Sala de Aula e as possibilidades de aplicabilidade como um princípio pedagógico na Educação Infantil por meio de uma Comunidade Aprendente. Foi utilizada a metodologia baseada na pesquisa-ação. Uma formação de professores por meio de uma Comunidade Aprendente foi realizada com os Educadores Multimeios sendo possível discutir sobre as práticas pedagógicas adotadas na Educação Infantil, bem como refletir e experenciar a utilização da Pesquisa em Sala de Aula como um princípio pedagógico para as crianças nas escolas da rede municipal de Igrejinha-RS.
\end{abstract}

Palavras-chave: Pesquisa em Sala de Aula; Comunidade Aprendente; Formação de professores.

Abstract: When the routine is planned and the activities are thought for children, it is waited to embrace their whole development, observing their singularities and characteristics. It is suggested to be observed the questionings, the curiosities, and the construction of knowledge, which children developed still in childhood. In this perspective, it is shown the question that guided this research: What emerges about Survey into the Classroom by the educators that work with in Early Childhood Education at the municipal schools in the city of Igrejinha-RS? For the development of this research, Multimedia Educators from the city of Igrejinha-RS were invited, which 
work with children from four to six years old in Child and Elementary Education Municipal Schools. The general objective was to provide a reflexive discussion on the Survey into the Classroom and the possibilities of application as a pedagogical principle in the Early Childhood Education through a Learning Community. For this investigation it was used a methodology based in research-action. A teachers' formation by the use of Learning Community was realized with the Multimedia Educators. In this research in conjunction with the Learning Community, it was possible to discuss about pedagogical practices adopted in the Child Education as well to reflect and experience the use of Classroom Research as a pedagogical principle for children at ages from four to six years old attended by the network of municipal schools in the city of Igrejinha-RS.

Keywords: Survey into the Classroom; Learning Community; Teacher training.

\section{INTRODUÇÃO}

A Educação Infantil está inserida na Educação Básica, atendendo crianças de zero a seis anos de idade, conforme a Lei $\mathrm{n}^{0} 9.394$ de 20 de novembro de 1996, artigo 29. Com isso, iniciou-se uma desassociação do assistencialismo às crianças atendidas nessa primeira etapa da Educação Básica. Segundo Brasil (1996, p.11), estabelece que "a educação infantil, primeira etapa da educação básica, tem como finalidade o desenvolvimento integral da criança até seis anos de idade, em seus aspectos físico, psicológico, intelectual e social, complementando a ação da família e da comunidade."

Dessa forma, reflete-se sobre a rotina diária das crianças que são acolhidas nas instituições de Educação Infantil. Além disso, sugere-se que o planejamento diário do professor possa abranger o desenvolvimento integral da criança, observando as suas singularidades e as suas características.

No entanto, ao ser planejada a rotina e ao ser pensada as atividades para as crianças, deve-se observar os questionamentos, as curiosidades e a construção do conhecimento que elas desenvolvem. Os educadores da Educação Infantil, comprometidos com o desenvolvimento integral da criança, devem diariamente ponderar as atividades elencadas no planejamento.

Nessa perspectiva, a questão que norteou essa pesquisa é: O que emerge sobre a Pesquisa em Sala de Aula pelos Educadores Multimeios que atuam na Educação Infantil nas escolas municipais de Igrejinha-RS? 
Para o desenvolvimento da pesquisa foram convidados os Educadores Multimeios $^{1}$ da rede municipal de Igrejinha-RS, que atuam com crianças de quatro a seis anos nas Escolas Municipais de Educação Infantil (EMEIs) e nas Escolas Municipais de Ensino Fundamental (EMEFs). Uma metodologia qualitativa foi utilizada baseada na pesquisa-ação, na qual o pesquisador juntamente com os professores, que foram convidados a participar da pesquisa, dialogaram e interagiram.

Considerando a importância para qualificar o trabalho docente nas instituições de ensino, responsáveis pelo atendimento das crianças que frequentam a Educação Infantil, essa pesquisa tem como objetivo geral proporcionar a discussão reflexiva acerca da Pesquisa em Sala de Aula e as possibilidades de sua aplicabilidade como princípio pedagógico na Educação Infantil por meio de uma Comunidade Aprendente.

Nas escolas os professores estão diariamente envolvidos nas diversas atividades com as crianças, com colegas e com a comunidade escolar, o que proporciona um constante aprendizado. Segundo Brandão (2005, p. 86), "querendo ou não (mas é melhor estar querendo) estamos, no conviver com outros e com o mundo, nos ensinando e aprendendo." Dessa forma, essa pesquisa foi realizada proporcionando questionários aos Educadores Multimeios e uma formação de professores por meio de uma Comunidade Aprendente.

\section{CONTEXTO DA PESQUISA E DETALHAMENTO DAS ATIVIDADES}

A rede municipal de Igrejinha-RS atendeu 1988 crianças no ano de 2019 (IGREJINHA, 2019) na primeira etapa da educação básica, a Educação Infantil. As crianças foram atendidas nas Escolas Municipais de Educação Infantil (EMEIs) e Escolas Municipais de Ensino Fundamental (EMEFs). Deste total, 1322 crianças receberam atendimento em turno integral, permanecendo na escola até doze horas diárias e matriculadas nas EMEIs, sendo as demais crianças da Educação Infantil atendidas em turno parcial, com carga horária de 4 horas diárias, nas EMEFs.

\footnotetext{
${ }^{1}$ Entende-se por Educador Multimeios, segundo a Lei Municipal no 5.128 (IGREJINHA, 2018), a docência na Educação Infantil e nas atividades de contraturno escolar (Programas de Assistência Integral a Criança Igrejinhense PRAICI / Centro Municipal de Atividades Educacionais - CEMAE).
}

Recebido em: $30 / 04 / 2020$

Aceito em: 19/11/2020 
Para o desenvolvimento da pesquisa foram convidados os Educadores Multimeios da rede municipal da cidade de Igrejinha-RS, que atuam com crianças de quatro a seis anos nas escolas municipais de Educação Infantil (EMEIs) e Ensino Fundamental (EMEFs). Um questionário aos Educadores Multimeios foi entregue, totalizando 43 educadores, tendo como propósito compreender os princípios que orientam a prática dos professores da Educação Infantil do município de Igrejinha-RS.

Esta pesquisa contou com a participação de dois tipos de Educadores Multimeios atuantes nas EMEIs e nas EMEFs: i) Educadores Multimeios Titulares, isto é, Educadores Multimeios que são regentes de turma; ii) Educadores Multimeios horaatividade que atendem as turmas durante a hora-atividade do Educador Multimeio Titular. Responderam ao questionário 24 Educadores Multimeios, conforme verifica-se

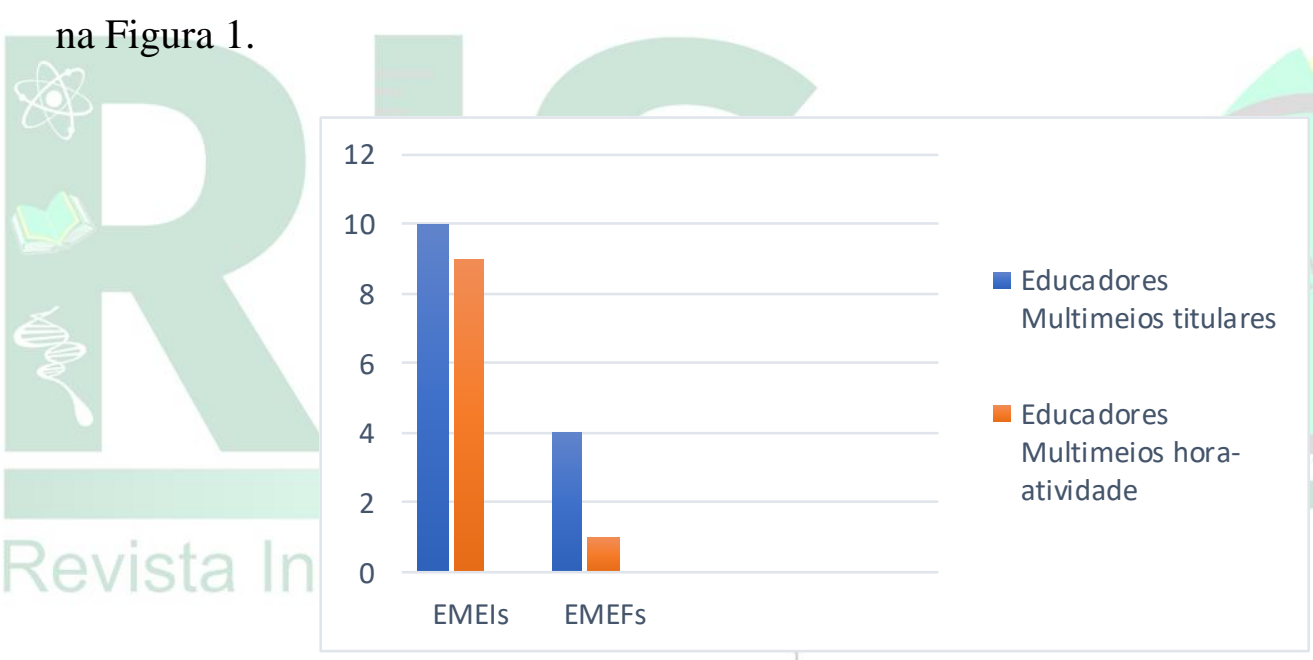

Figura 1- Identificação dos Educadores Multimeios que participaram desta investigação.

Por meio do gráfico, podemos constatar que 19 (79\%) Educadores Multimeios que participaram da pesquisa atuam nas Escolas de Educação Infantil e apenas cinco (21\%) atuam nas Escolas de Ensino Fundamental. Outros dados averiguados no questionário foram o tempo de experiência e a formação acadêmica dos participantes desta pesquisa, apresentados no Quadro 1. Ao caracterizar o tempo de docência foi verificado que os Educadores Multimeios possuem de um a 25 anos de experiência. Referente à formação acadêmica, a maioria dos participantes possui graduação completa e pós-graduação, estando alguns dos Educadores Multimeios ainda em processo de formação inicial em andamento.

Recebido em: $30 / 04 / 2020$ 
Edição Especial: XVI Encontro sobre Investigação na Escola - EIE

ISSN: 2595- $4520 \quad$ Vol. 4, n. 2. 2021

Quadro 1 - Tempo de docência e formação acadêmica dos participantes

\begin{tabular}{|c|c|c|}
\hline Tempo de experiência & Graduação & Pós-graduação \\
\hline Até 4 anos: 3 & Em andamento: 3 & $\begin{array}{c}\text { Gestão, Supervisão e } \\
\text { Orientação Escolar: } 2\end{array}$ \\
\hline 5-9 anos: 6 & Pedagogia: 7 & Psicopedagogia: 3 \\
\hline 10-14 anos: 13 & Teologia: 1 & $\begin{array}{c}\text { Educação Infantil e } \\
\text { anos iniciais: } 1\end{array}$ \\
\hline 25 anos: 1 & $\begin{array}{c}\text { Possui graduação, mas não } \\
\text { informou o curso: } 2\end{array}$ & $\begin{array}{c}\text { Possuica pós-graduação, mas } 1 \\
\text { não informou o curso: } 2\end{array}$ \\
\hline Não informou: 1 &
\end{tabular}

Segundo o Quadro 1, pode-se constatar que 58,3\% (14) dos participantes da pesquisa são Educadores Multimeios com 10 ou mais anos de experiência profissional. Outro dado importante é que 11 Educadores Multimeios possuem graduação, 10 são educadores pós-graduados em diferentes áreas de atuação e três estão cursando a graduação. Considerando que a formação acadêmica exigida para o ingresso no cargo de Educador Multimeios era de Ensino Médio completo, na modalidade Normal (Magistério), que formavam professores habilitados a lecionar nas turmas de Educação Infantil e nos primeiros anos do Ensino Fundamental, ressalta-se um engajamento positivo dos educadores na qualificação profissional. Embora ainda seja ofertado o Ensino Médio Normal (Magistério), atualmente a formação acadêmica exigida para o ingresso no cargo de Educador Multimeio é em nível superior no curso de Pedagogia.

Com a finalidade de mapear as experiências e as compreensões dos Educadores Multimeios sobre a Pesquisa em Sala de Aula, bem como compreender as possibilidades de emprego dessa proposta metodológica por esses educadores, foi realizado um questionário que contemplou perguntas abertas e fechadas. Aqui entendese por perguntas abertas aquelas que os participantes podem responder sem limite de palavras e as perguntas fechadas aquelas que apresentam alternativas para os participantes escolherem uma resposta, conforme foi sistematizado no Quadro 2. 
Quadro 2- Questionário para os Educadores Multimeios da Educação Infantil - Etapa 4 a 6 anos

\begin{tabular}{|c|c|c|}
\hline Questões abertas & Questões fechadas & $\begin{array}{c}\text { Tabulação questões } \\
\text { fechadas }\end{array}$ \\
\hline 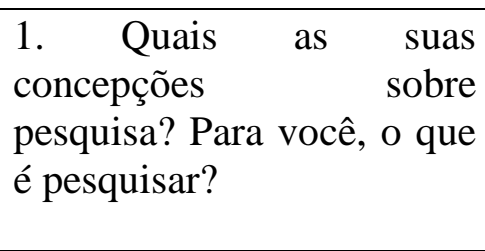 & $\begin{array}{l}\text { 2. Você já utilizou e/ou } \\
\text { utiliza a pesquisa em sala } \\
\text { de aula como metodologia } \\
\text { de ensino na Educação } \\
\text { Infantil? }\end{array}$ & $\begin{array}{l}2.67 \% \text { sim } \\
33 \% \text { não }\end{array}$ \\
\hline $\begin{array}{l}\text { 4. Em sua opinião, quais as } \\
\text { principais vantagens de } \\
\text { desenvolver pesquisas em } \\
\text { sala de aula com crianças } \\
\text { da Educação Infantil? }\end{array}$ & $\begin{array}{l}\text { 3. Você se sente seguro } \\
\text { para utilizar a pesquisa em } \\
\text { sala de aula como } \\
\text { metodologia de ensino na } \\
\text { Educação Infantil? }\end{array}$ & $\begin{array}{c}3.25 \% \text { sim } \\
21 \% \text { não } \\
54 \% \text { em parte }\end{array}$ \\
\hline $\begin{array}{l}\text { 5. Em sua opinião, quais as } \\
\text { principais desvantagens de } \\
\text { desenvolver pesquisas em } \\
\text { sala de aula com crianças } \\
\text { da Educação Infantil? }\end{array}$ & $\begin{array}{l}\text { 7. Você recebeu alguma } \\
\text { formação para utilizar a } \\
\text { pesquisa em sala de aula } \\
\text { como metodologia de } \\
\text { ensino na Educação } \\
\text { Infantil? }\end{array}$ & $\begin{array}{c}7.59 \% \text { sim } \\
33 \% \text { não } \\
08 \% \text { não responderam }\end{array}$ \\
\hline $\begin{array}{l}\text { 6. Relate as suas dúvidas e, } \\
\text { ou questionamentos que } \\
\text { você tem sobre utilizar a } \\
\text { pesquisa em sala de aula } \\
\text { como metodologia de } \\
\text { ensino tana nad Educação } \\
\text { Infantil. }\end{array}$ & $\begin{array}{l}\text { 8. Você gostaria de } \\
\text { participar de um grupo de } \\
\text { estudos sobre o trabalho } \\
\text { por projetos de pesquisa na } \\
\text { Educação Infantil? }\end{array}$ & $\begin{array}{c}8.63 \% \text { sim } \\
29 \% \text { não } \\
\text { 08\%não responderam }\end{array}$ \\
\hline
\end{tabular}

Conforme pode-se verificar no Quadro 2, a maioria dos educadores já utilizou e utiliza a Pesquisa em Sala de Aula como metodologia de ensino na Educação Infantil. A participante P4 relata que "Pesquisar traz novos conhecimentos, aprendizagem concreta". Segundo a participante P3 por meio da pesquisa ocorre a "construção de um conhecimento novo, de novas técnicas e a criação ou exploração de novas realidades, portanto, Pesquisar é: gerar e adquirir novos conhecimentos, responder a questionamentos, resolver problemas".

Ao analisar a Pesquisa em Sala de Aula, de acordo com Moraes, Galiazzi e Ramos (2012) ressalta-se o questionamento (pergunta) como o primeiro princípio. Sendo esse 
princípio, o questionamento, observado e evidenciado constantemente nas turmas de Educação Infantil.

Para Moraes, Galiazzi e Ramos

\begin{abstract}
Para que algo possa ser aperfeiçoado, é preciso criticá-lo, questioná-lo, perceber seus defeitos e limitações. É isto que possibilita pôr em movimento a pesquisa em sala de aula. $\mathrm{O}$ questionar se aplica a tudo que constitui o ser, quer sejam conhecimentos, atitudes, valores, comportamentos e modos de agir (MORAES; GALIAZZI; RAMOS, 2012, p.12).
\end{abstract}

Dessa maneira, destaca-se a possibilidade de aplicabilidade da Pesquisa em Sala de Aula como princípio pedagógico na Educação Infantil. Segundo Demo (1997, p. 14, grifo do autor), "assim, desmistificar a pesquisa há de significar também o reconhecimento da sua imisção natural na prática, para além de todas as possíveis virtudes teóricas, em particular da sua conexão necessária com a socialização do conhecimento".

Os Educadores Multimeios ao serem questionados sobre a segurança em utilizar a Pesquisa em Sala de Aula indicam que ainda não se sentem totalmente seguros em utilizar essa metodologia de ensino na Educação Infantil. Cabe ressaltar que um dos fatores que fundamenta a insegurança dos educadores é a propensão a metodologias tradicionais e a ausência de conhecimento sobre a Pesquisa em Sala de Aula. Para Martins Filho e Dornelles (2018, p.12): "Regra geral, os adultos têm muita resistência em abandonar a representação dominante que têm sobre as crianças, percebidas como seres psicológico e fisicamente imaturos, socialmente incompetentes e culturalmente ignorantes, e em aceitar o seu estatuto de atores sociais com plenos direitos de cidadania".

Alguns Educadores Multimeios demonstraram interesse em participar de um grupo de estudos, pois entenderam que eles seriam escutados e suas práticas consideradas, conforme Ribeiro (2013, p. 18): “A participação em Grupos de Estudo (GE) começou a ser mais interessante aos professores, pois permite a opinião livre de todos. Nos GE há a proposição de um trabalho que é desenvolvido e implementado pelos próprios autores, isto é, os participantes do grupo". Com isso realizou-se o convite para os Educadores Multimeios participarem de uma formação continuada por meio de uma Comunidade Aprendente. 
O segundo momento desta pesquisa foi a formação de professores por meio de uma Comunidade Aprendente que ocorreu entre julho e outubro de 2019 com uma carga horária de 40 horas, composta por encontros presenciais e à distância. Um convite foi entregue aos participantes desta pesquisa com informações básicas sobre o primeiro encontro, como data, horário, local.

Para Brandão, as Comunidades Aprendentes são grupos de vivência, tendo em vista que

\begin{abstract}
Ao lado da sala de aulas e da turma de alunos, vivemos situações pedagógicas em diferentes unidades de partilha da vida. Em cada uma delas e da interação entre todas elas é que ao longo de nossas vidas nós nos vemos às voltas com troca de significados, de saberes, de valores, de ideias e de técnicas disto e daquilo.

Assim é que podemos chamar cada uma destas unidades de vida e de destino de comunidades aprendentes (BRANDÃO, 2005, p. 87, grifos do autor).
\end{abstract}

A Comunidade Aprendente (CA) vem a contribuir com a formação de professores sobre a Pesquisa em Sala de Aula, pois conforme Galiazzi et al. (2017, p. 130), "Assume-se que as CA são grupos que se organizam em torno de interesses comuns, estabelecendo relações de pertencimento intensificadas ao longo do tempo. Atuam em torno de objetivos coletivos, compartilhando preocupações, problemas e afetos, a partir de uma área de conhecimento ou de prática". Por meio do compartilhamento de experiências, vivências, debates e estudos, discussão reflexiva e relações entre teoria e práticas pedagógicas sobre a Pesquisa em Sala de Aula na Educação Infantil.

O primeiro encontro da Formação Continuada de Professores: Pesquisa em Sala de Aula: um exercício na prática, ocorrido por meio de uma Comunidade Aprendente, foi realizado no dia 23 de julho de 2019. Neste dia compareceram, a professorapesquisadora, mais 4 participantes. Como início desta atividade, conversou-se sobre a proposta da CA, bem como definir as datas dos próximos encontros. A atividade foi construída coletivamente, como um dos princípios da Comunidade Aprendente. Após os participantes escreveram as suas concepções sobre a Pesquisa em Sala de Aula. Para finalizar o primeiro encontro foi propiciado um momento de escuta e trocas sobre o tema em questão entre os Educadores Multimeio.

A periodicidade dos encontros ocorreu com a alternância de encontros presenciais e à distância, sendo cinco encontros presenciais e cinco encontros à distância, 
totalizando dez encontros. Os encontros à distância ocorreram por intermédio da plataforma Google ${ }^{\circledR}$ sala de aula. O planejamento dos encontros ocorreu mediante as demandas, trajetória e discussões trazidas pelo o grupo de participantes, bem como as atividades que eram combinadas para serem realizadas.

\section{ANÁLISE E DISCUSSÃO DO RELATO}

Compor as concepções e as possibilidades de aplicabilidade acerca da Pesquisa em Sala de Aula na Educação Infantil foi a essência dessa pesquisa. Assim, para constituir a análise e discussão dos resultados utilizou-se análise do questionário inicial com os educadores, a interpretação das concepções dos participantes da pesquisa e análise das respostas do questionário final dos educadores participantes. Para análise das informações coletadas foi utilizada a Análise Textual Discursiva (ATD). De acordo com Moraes e Galiazzi (2016, p.13), a ATD possui como finalidade "produzir novas compreensões sobre os fenômenos e discursos".

Foram analisadas as seguintes questões abertas:

- Quais as suas concepções sobre pesquisa? Para você, o que é pesquisar?

- Em sua opinião, quais as principais vantagens de desenvolver pesquisas em sala de aula com as crianças da educação infantil.

- Em sua opinião, quais as principais desvantagens de desenvolver pesquisas em sala de aula com as crianças da educação infantil.

Após a ATD, emergiram três categorias principais e seis subcategorias, conforme apresentado no Quadro 3.

Quadro 3- Categorias e subcategorias emergentes da Análise Textual Discursiva

\begin{tabular}{|l|l|}
\hline \multicolumn{1}{|c|}{ Categoria Principal } & \multicolumn{1}{|c|}{ Subcategoria } \\
\hline 1. A formação continuada de professores & $\begin{array}{l}\text { a. A formação continuada de professores } \\
\text { reflexivos no processo de ensino. }\end{array}$ \\
\cline { 2 - 2 } $\begin{array}{l}\text { propicia reflexões sobre o processo de } \\
\text { ensino e aprendizagem }\end{array}$ & $\begin{array}{l}\text { e. As relações entre as práticas } \\
\text { pedagógicas e o processo de ensino e } \\
\text { aprendizagem. }\end{array}$ \\
\hline $\begin{array}{l}\text { 2. A Pesquisa em Sala de Aula como } \\
\text { princípio pedagógico na Educação Infantil }\end{array}$ & $\begin{array}{l}\text { b. Relações entre a rotina na educação } \\
\text { infantil e as vantagens e/ou dificuldades } \\
\text { da Pesquisa em Sala de Aula. }\end{array}$ \\
\hline
\end{tabular}

Recebido em: 30 /04/ 2020 


\begin{tabular}{|l|l|}
\hline & $\begin{array}{l}\text { c. A inserção da Pesquisa em Sala de Aula } \\
\text { como princípio pedagógico. }\end{array}$ \\
\hline $\begin{array}{l}\text { 3. O protagonismo das crianças nos } \\
\text { processos de pesquisa na Educação } \\
\text { Infantil }\end{array}$ & $\begin{array}{l}\text { d. As interações e brincadeiras propiciam } \\
\text { o protagonismo das crianças no seu } \\
\text { desenvolvimento e aprendizagens. }\end{array}$ \\
\cline { 2 - 3 } & $\begin{array}{l}\text { f. A Pesquisa em Sala de Aula oportuniza } \\
\text { o protagonismo das crianças. }\end{array}$ \\
\hline
\end{tabular}

Destaca-se que como resultado da análise emergiram as categorias principais, sendo construído a partir destas categorias a interpretação das concepções dos participantes da pesquisa. Ao serem questionados sobre as principais vantagens em desenvolver a Pesquisa em Sala de Aula com crianças da Educação Infantil destaca-se que os Educadores Multimeio relatam diversas vantagens, conforme P2 "A partir da pesquisa acredito que trabalhamos a partir da curiosidade e interesse dos alunos, tornando a aprendizagem significativa, com a construção coletiva do conhecimento. Também contribuímos para a formação de pessoas-cidadãos mais críticos, interativos e atuantes na sociedade”. Segundo o participante P4 por meio da Pesquisa em Sala de Aula podemos "Potencializar a busca; desenvolver habilidades; permite a reflexão; impulsiona a aprendizagem". Ressalta-se as vantagens e as possibilidades de aplicabilidade da Pesquisa em Sala de Aula como princípio pedagógico na rotina diária das crianças da Educação Infantil. Demo afirma que

o que melhor distingue a educação escolar de outros tipos de espaços educativos é o fazer-se e refazer-se na e pela pesquisa. A própria vida como tal é um espaço naturalmente educativo, à medida que induz à aprendizagem constante, burila a têmpera das pessoas, forma no sofrimento e na experiência acumulada. A família, mais do que ninguém, educa todo o dia e toda hora, sendo a instância mais responsável pelas condições de emancipação dos filhos. A roda de amigos, a reunião no bar, o ambiente de trabalho etc., também são lugares possivelmente educativos. Entretanto, todos esses espaços e agentes educam através de outros expedientes que não seja a pesquisa. (DEMO, 2011, p.7).

Portanto para que o educador possa educar através de processos de pesquisa é aconselhável que supere práticas tradicionais que visam a transmissão do conhecimento. Desse modo, a formação continuada de educadores por meio da Comunidade Aprendente foi a maneira de proporcionar a reflexão sobre as práticas adotadas, bem 
como as possibilidades de inserir a Pesquisa em Sala de Aula como princípio pedagógico na Educação Infantil.

\section{CONSIDERAÇÕES FINAIS}

Por meio do desenvolvimento da Comunidade Aprendente com os Educadores Multimeio foi possível discutir sobre as práticas pedagógicas adotadas na Educação Infantil, bem como refletir e experienciar a utilização da Pesquisa em Sala de Aula como princípio pedagógico para as crianças de quatro a seis anos atendidas nas escolas da rede municipal de Igrejinha-RS.

Cabe ressaltar que ao vivenciar a Pesquisa em Sala de Aula como princípio pedagógico, os Educadores Multimeio participantes da pesquisa confirmaram as vantagens da utilização dessa proposta pedagógica. Constataram que é possível aplicar a Pesquisa em Sala de Aula com as crianças da Educação Infantil. Para isso, é importante estar atento aos questionamentos e curiosidades que fazem parte da rotina diária das crianças.

Destaca-se que a formação continuada por meio de uma Comunidade Aprendente foi desenvolvida sobre a Pesquisa em Sala de Aula com Educadores Multimeio que atuam Educação Infantil, porém tem potencial para utilizar em outras etapas de ensino e em/diversas áreas de atuação. É importante ressaltar que todos os participantes dessa formação continuada construíram novos conhecimentos que são importantes para a qualificação da sua prática profissional, bem como para atentarem aos os questionamentos, as curiosidades e a construção do conhecimento das crianças na Educação Infantil.

\section{REFERÊNCIAS}

BRANDÃO, Carlos Rodrigues. Encontros e caminhos: formação de educadoras (es) ambientais e coletivos educadores. Brasília: MMA, Diretoria de Educação Ambiental, 2005, p. 83-92. Disponível em: <http://www.mma.gov.br/estruturas/educamb/_arquivos/encontros.pdf >. Acesso em: jul. 2019. 
BRASIL. Ministério de Educação e Cultura. LDB - Lei no 9394/96, de 20 de dezembro de 1996. Estabelece as diretrizes e bases da Educação Nacional. Brasília: MEC, 1996.

IGREJINHA. Projeto Escola. Igrejinha: Secretaria da Educação, 2019.

DEMO, Pedro. Educar pela pesquisa. 10. ed. Campinas, SP: Autores Associados, 2011.

DEMO, Pedro. Pesquisa: princípio científico e educativo. 5 ed. São Paulo: Cortez, 1997.

GALIAZZI, Maria do Carmo et al. Narrativas de Comunidades Aprendentes em Educação Ambiental. AMBIENTE \& EDUCAÇÃO Revista de Educação Ambiental vol. $22 \quad$ n. 2017.2 Disponível em: < $\underline{\text { https://periodicos.furg.br/ambeduc/article/view/7442/5097> }}$

GIL, Antônio Carlos. Como elaborar projetos de pesquisa. 4. ed. São Paulo: Atlas, 2002.

MARTINS FILHO, Altino José. Minúcias da vida cotidiana na prática docente. In: MARTINS FILHO, Altino José, DORNELLES, Leni Vieira (Orgs). Lugar de criança na escola e na família: a participação e o protagonismo infantil. Porto Alegre: Mediação, 2018.

MORAES, Roque. GALIAZZI, Maria do Carmo. Análise Textual Discursiva. Ijuí: Ed. Unijuí, 2016.

MORAES, Roque; GALIAZZI, Maria do Carmo; RAMOS, Maurivan Guntzel. Pesquisa em sala de aula: fundamentos e pressupostos. In: MORAES, Roque, LIMA, Valderez M. do R. Pesquisa em sala de aula: tendências para a educação em novos tempos. 3. ed. Porto Alegre: EDIPUCRS, 2012.

RIBEIRO, Marcus Eduardo Maciel. O papel de uma comunidade de prática de professores na promoção do interesse dos alunos em aulas de Química. 2017. $251 \mathrm{f}$. Tese (Doutorado em Educação em Ciências e Matemática) - Pontifícia Universidade Católica do Rio Grande do Sul, Porto Alegre, 2017. 